\title{
Integrating Behavioral Health Services into Primary Care: Spotlight on the Primary Care Behavioral Health (PCBH) Model of Service Delivery
}

\author{
Christopher L. Hunter ${ }^{1}$ Anne C. Dobmeyer ${ }^{2}$. Jeffrey T. Reiter ${ }^{3}$
}

Published online: 17 January 2018

(c) This is a U.S. Government work and not under copyright protection in the US; foreign copyright protection may apply 2018

\section{Why This Special Issue?}

In recent years in the United States (US), there has been a shift in primary care service delivery through patient-centered medical home (PCMH) implementation, a focus on the Triple Aim, and the passage of the Patient Protection and Affordable Care Act (Baird et al., 2014; National Committee for Quality Assurance [NCQA], 2014; Nielsen, Gibson, Buelt, Grundy, \& Grumbach, 2015). These efforts have set the stage for payers, primary care service professionals, and patients to expect integrated behavioral health services as an essential component of primary care.

Three prominent models of integrating behavioral health services in primary care include the Screening, Brief Intervention and Referral to Treatment (SBIRT) model, the Collaborative Care model (CoCM), and the Primary Care Behavioral Health (PCBH) model. The SBIRT model focuses on patients with risky, but not yet problematic substance use, and has received ample review on model components and effectiveness (e.g., Moyer, 2013). The CoCM largely focuses on patients with depression and anxiety and has been widely described and evaluated with a review of 79 randomized controlled trials summarizing model impact (Archer et al., 2012). The PCBH model has also been described in a number of publications (e.g., Gatchel \& Oordt, 2003; Hunter, Goodie, Oordt, \& Dobmeyer, 2017;

Christopher L. Hunter

christopher.1.hunter16.mil@mail.mil

1 Defense Health Agency, Clinical Support Division, PatientCentered Medical Home Branch, 7700 Arlington Boulevard, Suite 5101, Falls Church, VA 22042, USA

2 Psychological Health Center of Excellence, Defense Health Agency, Falls Church, VA, USA

3 College of Health Solutions, Doctor of Behavioral Health (DBH) Program, Arizona State University, Phoenix, AZ, USA
Robinson \& Reiter, 2016; Serrano, 2015; Strosahl, 1998, 2005). It has been implemented across the US in large healthcare systems (e.g., Hunter, Goodie, Dobmeyer, \& Dorrance, 2014; Kearney, Post, Pomerantz, \& Zeiss, 2014), community health organizations (e.g., Freeman, 2011; Kanapaux, 2004), family medicine residency programs (Hill, 2015), university health centers (e.g., Funderburk, Fielder, DeMartini, \& Flynn, 2012; Sadock, Auerbach, Rybarczyk, \& Aggarwal, 2014), and homeless clinics (Ogbeide, Buck \& Reiter, 2014). There is also a growing number of PCBH model studies examining patient and implementation outcomes (Hunter et al., 2017).

Despite these efforts, there remains confusion in the literature and professional community regarding the core goals, tenants, and strategies of the PCBH model. In an attempt to remedy this situation, this special issue is designed to serve as a one-stop information foundation for the PCBH model overview and definition; current state of the science; ethical considerations; diverse intervention strategies, training, and workforce development; and payment, legislative, and policy developments. We hope that this collection of articles will achieve a number of goals. One major aim is to provide the field with a concise definition of the PCBH model to aid in understanding key model features using consistent terminology. Such a definition could serve as a benchmark for clinicians, administrators, and researchers in determining what the PCBH model "is" and "is not" across diverse settings and organizations, and more clearly distinguish it from other models of integrated care and from co-located care. This is a prerequisite for the continued progression and dissemination of the model. A second major goal of the special issue is to provide comprehensive summaries of the major challenges currently facing proponents of the PCBH model. These include lack of clear ethical guidance specific to integrated service delivery models, difficulties with reimbursement and funding due to unsupportive policies and regulations, lack of a sufficiently trained behavioral health and primary care 
workforce prepared to implement the PCBH model, and a research base that, although growing, suffers from a number of limitations. Finally, drawing from these discussions of challenges, the special issue hopes to serve as a call to action for moving the PCBH model forward, through stimulating ideas and activities promoting legislative and policy reform, education and training expansion, ethical guidance development, and additional, high-quality research targeting key integration questions.

This special issue is composed of nine invited manuscripts submitted by leaders in the field of PCBH model integration. Lead authors were asked to select collaborators and to submit manuscripts focusing on a PCBH model content area we selected to achieve the goals of the special issue. The authors represent a diverse array of professional settings and PCBH model activities, including early developers of the PCBH model; educators in family medicine and psychology training programs; leaders of integration efforts in large government, commercial, and community healthcare organizations; international PCBH model consultants and trainers; academic researchers; and physicians and psychologists practicing the PCBH model.

Reiter, Dobmeyer, and Hunter (2017) provide a detailed overview of the PCBH model. Included is a concise operationalized definition of the model, developed from examination of multiple published resources and consultation with nationally recognized PCBH model experts. Reiter et al. (2017) also provide a detailed description of the key PCBH model components under the framework of the acronym GATHER, where "G" is for "Generalist approach," "A" is for "Accessibility," "T" is for "Team-based," " $\mathrm{H}$ " is for "High productivity," "E" is for "Educator," and " $R$ " is for "Routine." Each component is further fleshed out with clinical strategies and clinical examples in line with the core component and the rationale for those strategies. We make a particular point of explaining the population health basis of the model. Finally, we also provide a brief comparison of the $\mathrm{PCBH}$ model to other integration approaches and a focused summary of PCBH model research.

Hunter et al. (2017) address the science behind the model in the second article. They provide a qualitative review of published PCBH model research on patient (satisfaction, functioning, symptoms) and implementation (acceptability, adoption, appropriateness, cost, feasibility, fidelity, penetration, sustainability) outcomes. A summary of 29 studies with unique samples is included in the review. Research gaps are identified and ways to address those gaps through multiple levels of research participation including patients, practitioners, healthcare systems, and academic researchers are discussed.

Runyan, Carter-Henry, and Ogbeide (2017) take on the complex topic of ethics. They highlight conflicting ethical principles and guidelines occurring with PCBH model interprofessional collaboration. They review the extant literature across disciplines, identify gaps, and propose new ethical guidelines to bridge those gaps. Runyan et al. discuss common ethical dilemmas unique to the PCBH model of service delivery with case examples and illustrate the application of the newly proposed guidelines to effectively navigate those dilemmas.

Sandoval, Bell, Khatri, and Robinson (2017) provide a deep dive on patient-centered care delivery strategies in the PCBH model that can improve clinical outcomes, cost, and patient and primary care provider satisfaction with services. They discuss the importance of behavioral health consultants (BHCs) as integral clinical pathway team members to maximize pathway impact. The importance of BHC engagement for depression, persistent pain, alcohol misuse, obesity, insomnia, hypertension, and social determinants of health clinical pathways are reviewed. They conclude with a clinical pathway development primer.

The PCBH model behavioral health workforce and training needs are addressed by Serrano, Cordes, Cubic, and Daub (2017) who highlight the challenge of PCBH model behavioral health workforce development with professionals that are not typically trained to work in primary care as part of the team providing focused, high-volume service delivery. They review current certificate programs, technical assistance programs, and on-the-job training efforts to retrain behavioral health professionals to effectively work as BHCs. With a look to the future, they discuss eight workforce recommendations believed necessary in order for the PCBH model to sustainably proliferate. Recommendations include (1) the development of an interprofessional certification body for PCBH training programs, (2) integration of PCBH model-specific curricula in graduate studies, (3) integration of program development skill building in curricula, (4) efforts to develop faculty for PCBH model awareness, (5) intentional efforts to draw students to graduate programs for PCBH model training, (6) a national employment clearinghouse, (7) efforts to coalesce current knowledge around the provision of technical assistance to sites, and (8) workforcespecific research efforts.

Rounding out $\mathrm{BHC}$ workforce development and training, Robinson et al. (2017) address what the rest of the primary care team needs to know and do to work effectively in the PCBH model. Drawing on a diverse set of experiences, the authors detail a set of competency tools for clinic leaders, primary care providers, and nurses to use in assessing current knowledge and skills and setting change targets. The competency domains include clinical practice, practice management, consultation, documentation, team performance, and administrative skills. The tools described were developed by researchers working to disseminate evidencebased interventions in primary care clinics that included fully integrated BHCs. They conclude by detailing how two 
very different healthcare systems approached PCBH model implementation and expansion.

Legislation and policy can hinder or promote the implementation of the PCBH model. Freeman, Hudgins, and Hornberger (2017) review how widespread implementation of the PCBH model has been restricted by outmoded policies and regulatory barriers. Based on their state and healthcare system experience as well as initiatives across the US, they discuss the necessity for policy change, detailing the policy issues and barriers that serve to limit the practice of the PCBH model. They highlight innovative state approaches to foster integrated practice and discuss the compatibility of the PCBH model with the nation's health care reform agenda. They finish with a list of recommendations addressing feefor-service billing, coding, carve-outs, Medicaid, federal/ state funding, federal policy, and advocacy to facilitate the future viability of the PCBH model regardless of the organizational structure or funding environment.

Arguably, one of the primary barriers to PCBH model implementation is funding. Freeman, Manson, Howard, and Hornberger (2017) address this issue and provide an overview of the history of PCBH model financing problems and the current PCBH model funding landscape. They discuss the infrastructure (e.g., electronic health record) changes they believe are needed to support PCBH model service delivery and how emerging trends in healthcare financing are impacting the model. They conclude with a list of future PCBH model funding strategies (e.g., pay-for-performance) that could help remove the funding barrier.

In this special issue, we sought to bring together leading PCBH model subject matter experts to address important content areas that need ongoing focus for aiding the field in understanding and using the PCBH model well. We hope that these articles will serve as an up-to-date foundation, helping launch quality research, effective training, and dissemination and implementation of the PCBH model.

Disclaimer The opinions and statements in this article are the responsibility of the authors, and such opinions and statements do not necessarily represent the policies of the Department of Health and Human Services, Department of Defense, or their agencies.

\section{Compliance with Ethical Standards}

Conflict of interest Christopher L. Hunter and Anne C. Dobmeyer declare that they have no conflict of interest. Jeffrey T. Reiter declares that he receives book royalties and consulting fees.

Human and Animal Rights and Informed Consent No animal or human studies were carried out by the authors for this article.

\section{References}

Archer, J., Bower, P., Gilbody, S., Lovell, K., Richards, D., Gask, L., ... Coventry, P. (2012). Collaborative care for depression and anxiety problems. Cochrane Database of Systematic Reviews. https://doi. org/10.1002/14651858.CD006525.pub2.

Baird, M., Blount, A., Brungardt, S., Dickinson, P., Dietrich, A., Epperly, T., ... deGruy, F. (2014). Joint principles: Integrating behavioral health care into the patient-centered medical home. Annals of Family Medicine, 12, 183-185.

Freeman, D. (2011). The behavioral health medical home. In N. A. Cummings \& W. T. O'Donohue (Eds.), Understanding the behavioral healthcare crisis: The promise of integrated care and diagnostic reform (pp. 250-265). Florence, KY: Routledge.

Freeman, D. S., Hudgins, C., \& Hornberger, J. (2017). Legislative and policy developments and imperatives for advancing the Primary Care Behavioral Health (PCBH) model. Journal of Clinical Psychology in Medical Settings.

Freeman, D. S., Manson, L., Howard, J., \& Hornberger, J. (2017). Financing the primary care behavioral health model. Journal of Clinical Psychology in Medical Settings.

Funderburk, J. S., Fielder, R. L., DeMartini, K. S., \& Flynn, C. A. (2012). Integrating behavioral health services into a university health center: Patient and provider satisfaction. Families, Systems, and Health. https://doi.org/10.1037/a0028378.

Gatchel, R. J., \& Oordt, M. S. (2003). Clinical health psychology and primary care: Practical advice and clinical guidance for successful collaboration. Washington DC: American Psychological Association.

Hill, J. (2015). Behavioral health integration: Transforming patient care, medical resident education and physician effectiveness. The International Journal of Psychiatry in Medicine, 50(1), 36-39.

Hunter, C. L., Funderburk, J. S., Polaha, J., Bauman, D., Goodie, J. L., \& Hunter, C. M. (2017). Primary care behavioral health (PCBH) model research: Current state of the science and a call to action. Journal of Clinical Psychology in Medical Settings. https://doi. org/10.1007/s10880-017-9512-0.

Hunter, C. L., Goodie, J. L., Dobmeyer, A. C., \& Dorrance, K. A. (2014). Tipping points in the Department of Defense's experience with psychologists in primary care. American Psychologist, 69, 388-398.

Hunter, C. L., Goodie, J. L., Oordt, M., \& Dobmeyer, A. C. (2017). Integrated behavioral health in primary care: Step-by-step guidance for assessment and intervention (2nd ed.). Washington, DC: American Psychological Association.

Kanapaux, W. (2004). The road to integrated care: Commitment is the key: Tennessee CMHC demonstrates promise of co-located behavioral and primary care. Behavioral Healthcare Tomorrow, 13, 10.

Kearney, L. K., Post, E. P., Pomerantz, A. S., \& Zeiss, A. M. (2014). Applying the interprofessional patient aligned care team in the Department of Veterans Affairs. American Psychologist, 69, 399-408.

Moyer, V. A. (2013). Screening and behavioral counseling interventions in primary care to reduce alcohol misuse: U.S. Preventive Services Task Force recommendation statement. Annals of Internal Medicine, 159, 210-218.

National Committee for Quality Assurance [NCQA] (2014). Standards and guidelines for NCQA's patient-centered medical home (PCMH) 2014. Retrieved from http://store.ncqa.org/index. php/2014-pcmh-standards-and-guidelines-epub-single-user.html.

Nielsen, M., Gibson, A., Buelt, L., Grundy, P., \& Grumbach, K. (2015). The patient-centered medical home's impact on cost and quality: Annual review of the evidence. Retrieved from https://www.pcpcc.org/resource/ patient-centered-medical-homes-impact-cost-and-quality. 
Ogbeide, S., Buck, D. S., \& Reiter, J. (2014). Mapping new territory: Implementing the Primary Care Behavioral Health (PCBH) model in homeless shelter clinics. Lecture presented to the Collaborative Family Healthcare Association conference, Portland, OR.

Reiter, J. T., Dobmeyer, A. C., \& Hunter, C. L. (2017). The Primary Care Behavioral Health (PCBH) model: An overview and operational definition. Journal of Clinical Psychology in Medical Settings.

Robinson, P. J., Oyemaja, J., Beachy, B., Goodie, J. L., Sprague, L., Bell, J., ... Ward, C. (2017). Creating a primary care workforce: Strategies for leaders, clinicians, and nurses. Journal of Clinical Psychology in Medical Settings.

Robinson, P. J., \& Reiter, J. T. (2016). Behavioral consultation and primary care: A guide to integrating services (2nd edn.). Geneva: Springer International.

Runyan, C. N., Carter-Henry, S., \& Ogbeide, S. (2017). Ethical challenges unique to the primary care behavioral health (PCBH) model. Journal of Clinical Psychology in Medical Settings. https://doi.org/10.1007/s10880-017-9502-2.

Sadock, E., Auerbach, S. M., Rybarczyk, B., \& Aggarwal, A. (2014). Evaluation of integrated psychological services in a university-based primary care clinic. Journal of Clinical Psychology in Medical Settings, 21, 19-32.

Sandoval, B. E., Bell, J., Khatri, P., \& Robinson, P. J. (2017). Toward a unified approach: Uniting diverse primary care strategies under the primary care behavioral health (PCBH) model. Journal of Clinical Psychology in Medical Settings.

Serrano, N. (2015). The implementer's guide to primary care behavioral health. Madison, WI: Madison Community Health Center, Inc.

Serrano, N., Cordes, C., Cubic, B., \& Daub, S. (2017). The state and future of the primary care behavioral health model of service delivery workforce. Journal of Clinical Psychology in Medical Settings. https://doi.org/10.1007/s10880-017-9491-1.

Strosahl, K. (1998). Integrating behavioral health and primary care services: The primary mental health care model. In A. Blount (Ed.), Integrated primary care: The future of medical and mental health collaboration (pp. 139-166). New York: Norton.

Strosahl, K. (2005). Training behavioral health and primary care providers for integrated care: A core competency approach. In W. T. O’Donohue, M. R. Byrd, N. A. Cummings \& D. A. Henderson (Eds.), Behavioral integrative care: Treatments that work in primary care settings (pp. 15-52). New York: Brunner-Routledge. 